$\begin{gathered}\text { Науковий вісник НЛТУ України } \\ \text { Scientific Bulletin of UNFU } \\ \text { https://nv.nltu.edu.ua }\end{gathered}$
$\begin{gathered}\text { https://doi.org/10.15421/40280617 } \\ \text { Article received 15.06.2018 p. }\end{gathered}$
ISSN 2519-2477 (online)
Article accepted 25.06.2018 p.
Удк 541.128.13

І. І. Шпирка1, Р. В. Небесний1, З. Г. Піх ${ }^{1}$ В. В. Сидорчук², С. В. Халамейда², О. В. Цимбаліста1, Х. Р. Хома1

${ }^{1}$ Національний університет "Львівська політехніка", м. Львів, Украӥна ${ }^{2}$ Інститут сорбиії та проблем ендоекології НАН Украӥни, м. Київ, Україна

\title{
ОДЕРЖАННЯ АКРИЛОВОЇ КИСЛОТИ АЛЬДОЛЬНОЮ КОНДЕНСАЦІЄЮ ОЦТОВОЇ КИСЛОТИ 3 ФОРМАЛЬДЕГІДОМ У ПРИСУТНОСТІ В-P-W-V-0x КАТАЛІЗАТОРІВ НА МЕЗОПОРИСТИХ НОСІЯХ
}

\begin{abstract}
Досліджено вплив різних типів мезопористих носіїв для В-P-W-V-Oㅊ каталізаторів, а саме: $\mathrm{SiO}_{2}, \mathrm{TiO}_{2}, \mathrm{ZrO}_{2}, \mathrm{SnO}_{2}$ $\mathrm{TiO}_{2}$ та $\mathrm{Al}_{2} \mathrm{O}_{3}$ на їх ефективність у процесі альдольної конденсації оцтової кислоти з формальдегідом з утворенням акрилової кислоти. Каталізатори готували методом просочення носія насиченим розчином компонентів активної фази. Каталітичні підготовано одержаних каталізаторів досліджено в реакції альдольної конденсації оцтової кислоти з формальдегідом у температурному діапазоні від 573 до $673 \mathrm{~K}$, часі контакту 8 с за еквімолярного співвідношення вихідних реагентів. Встановлено вплив умов здійснення процесу (температури та часу контакту) на параметри процесу конденсації оцтової кислоти 3 формальдегідом; визначено оптимальні умови здійснення процесу. Оптимальними умовами здійснення процесу конденсації оцтової кислоти з формальдегідом в акрилову кислоту є температура 648 К та час контакту 8 с на каталізаторі з використанням носія $\mathrm{TiO}_{2}$ анатаз з $\mathrm{TiO}(\mathrm{OH})$. У зазначених умовах вдалося досягти виходу акрилової кислоти $49 \%$ за селективності іiі утворення $94 \%$ та конверсії оцтової кислоти $52 \%$. Показано, що каталізатори на основі носіїв різної природи 3 розміром пор близько 10 нм дає змогу одержувати акрилову кислоту з високим виходом та селективністю. Водночас, вихід цільового продукту, як і селективність його утворення під час використання різних носіїв, відрізняється, що свідчить про вплив природи носія на каталітичні властивості.
\end{abstract}

Ключові слова: акрилатні мономери; гетерогенний каталіз; тверді каталізатори; метод просочення.

Вступ. Акрилова кислота (АК) - це цінний продукт у галузі органічного синтезу, якого широко використовують у виробництві високоякісних фарб і лаків, органічного скла, як допоміжну речовину в текстильній промисловості, у виробництві суперабсорбентів, у медицині (Danner, et al., 2008; Zuo, et al., 2015; Shashkova, et al., 2016; Flégeau, et al., 2017; Patent 7563265 US. 2009; Patent 7655706 US. 2010; Patent 7553918 US. 2009). Світове виробництво АК становить понад 5 млн т на рік, i, згідно з маркетинговими дослідженнями, ринок акрилатних мономерів постійно зростає (Li, \& Zhang, 2016). Одним із найперспективніших способів виробництва АК є альдольна конденсація оцтової кислоти (ОК) з формальдегідом (ФА) (Zhyznevskyy, et al., 2010). Перевагами одержання АК методом альдольної конденсації $\epsilon$ :

- розширення сировинної бази синтезу АК та можливість знизити залежність від нафтових джерел сировини;

- більш ефективне використання сировинних ресурсів, що досягається завдяки вищій селективності утворення цільового продукту.

Проте АК методом альдольної конденсації не виробляють у промислових масштабах через порівняно низьку ефективність відомих каталізаторів, короткий термін їх служби та закоксовування поверхні каталізаторів (Раtent 0343319 US. 2014).

Ключовою проблемою на шляху промислового впровадження виробництва АК методом альдольної конденсації $\epsilon$ розроблення ефективних каталізаторів. Реакції альдольної конденсації карбонільних сполук можуть відбуватися на активних центрах каталізатора як основного, так і кислотного типів. Здебільшого застосування каталізаторів основного типу характеризується прийнятною селективністю утворення цільово-

\section{Інформація про авторів:}

Шпирка Ірина Іванівна, аспірант, кафедра технології органічних продуктів. Email: iryna.i.shpyrka@lpnu.ua

Небесний Роман Володимирович, канд. техн. наук, пров. науковий співробітник, кафедра технології органічних продуктів. Email: nebesnyi@Ip.edu.ua

Піх Зорян Григорович, д-р хім. наук, професор, завідувач кафедри технології органічних продуктів. Email: pikh@lp.edu.ua Сидорчук Володимир Васильович, канд. хім. наук, пров. науковий співробітник. Email: bilychi@ukr.net

Халамейда Світлана В'ячеславівна, канд. хім. наук, ст. науковий співробітник. Email: bilychi@ukr.net Цимбаліста Оксана Володимирівна, магістрант, кафедра технології органічних продуктів. Email: oksana.cimbalista@gmail.com Хома Христина Романівна, магістрант, кафедра технології органічних продуктів. Email: khomakhrystyna1996@gmail.com Цитування за ДСтУ: Шпирка І. І., Небесний Р. В., Піх З. Г., Сидорчук В. В., Халамейда С. В., Цимбаліста О. В., Хома Х. Р. Одержання акрилової кислоти альдольною конденсацією оцтової кислоти з формальдегідом у присутності B-P-W-V-O каталізаторів на мезопористих носіях. Науковий вісник НЛтУ України. 2018, т. 28, № 6. С. 89-92.

Citation APA: Shpyrka, I. I., Nebesnyi, R. V., Pikh, Z. G., Sydorchuk, V. V., Khalameida, S. V., Tsymbalista, O. V., \& Khoma, K. R. (2018). Acrylic acid obtaining by aldol condensation of acetic acid with formaldehyde in the presence of $B-P-W-V-O_{x}$ catalysts on mesoporous carrier. Scientific Bulletin of UNFU, 28(6), 89-92. https://doi.org/10.15421/40280617 
го продукту (АК), проте активність таких каталізаторів $\epsilon$ порівняно невисокою (Bailey, Montag \& Yoo, 1992). Каталізатори кислотного типу, навпаки, забезпечують вищу конверсію вихідних реагентів (ОК, ФА), проте їх використання супроводжується утворенням значної кількості побічних продуктів (Ai, et al., 2003). Але, незважаючи на певний успіх у розвитку каталізаторів, бажаний рівень їх ефективності ще не досягнуто. Тому важливим $\epsilon$ поряд 3 використанням оптимальних кислотно-основних властивостей поверхні каталізаторів встановити та використовувати додаткові методи контролю за селективністю та активністю каталізаторів.

Тому зроблено припущення, що підвищити ефективність каталізатора можна способом нанесення активної фази каталізатора на носії різних типів зі зіставним діаметром пор.

У попередніх дослідженнях (Nebesnyi, et al., 2013) встановлено, що каталізатор складу В-P-W-V-O п показує високу ефективність у процесі газофазної конденсації оцтової кислоти з формальдегідом в акрилову кислоту та встановлено значний вплив поруватої структури каталізаторів на його перебіг (Nebesnyi, et al., 2016). Biдомо, що природа носія також може впливати на процес (Skubiszewska-Zieba, Khalameida \& Sydorchuk, 2016), тому вирішили використати розроблену активну фазу каталізатора і нанести іiі на різної природи носії із схожими параметрами поруватої структури. Тому вирішено продовжити розробляти каталітичні системи для реакції альдольної конденсації та застосовувати різні види носіїв з близьким діаметром пор до $10 \mathrm{Hм}: \mathrm{SiO}_{2}$, $\mathrm{TiO}_{2}$ анатаз $3 \mathrm{TiO}(\mathrm{OH}), \mathrm{ZrO}_{2}, \mathrm{SnO}_{2}-\mathrm{TiO}_{2}, \mathrm{Al}_{2} \mathrm{O}_{3}$ i активною фазою $\mathrm{B}-\mathrm{P}-\mathrm{W}-\mathrm{V} / \mathrm{O}_{\mathrm{x}}$.

Мета дослідження полягає у встановленні впливу різних носіїв: $\mathrm{SiO}_{2}, \mathrm{TiO}_{2}$ анатаз $3 \mathrm{TiO}(\mathrm{OH}), \mathrm{ZrO}_{2}, \mathrm{SnO}_{2}$ $\mathrm{TiO}_{2}, \mathrm{Al}_{2} \mathrm{O}_{3}$ на ефективність у процесі альдольної конденсації ОК з ФА з утворенням АК.

Матеріали та методи дослідження. Для досліджень процесу альдольної конденсації ОК з ФА приготовано каталітичні системи на основі різних носіїв методом просочування насиченим розчином компонентів активної фази В-P-W-V/O . Як носії використано $\mathrm{SiO}_{2}$, $\mathrm{TiO}_{2}$ анатаз $3 \mathrm{TiO}(\mathrm{OH}), \mathrm{ZrO}_{2}, \mathrm{SnO}_{2}-\mathrm{TiO}_{2}, \mathrm{Al}_{2} \mathrm{O}_{3}$. Каталізатори готували методом просочення носія насиченим розчином компонентів активної фази. Атомне співвідношення компонентів у каталізаторі B:P:(W+V) становить $3: 1: 0,3$; атомне співвідношення $\mathrm{W}: \mathrm{V}=2: 3$. Каталітичні властивості одержаних каталізаторів досліджено в реакції альдольної конденсації ОК з ФА в температурному діапазоні від 573 до $673 \mathrm{~K}$, часі контакту 8 с за еквімолярного співвідношення вихідних реагентів.

Як джерело ФА для дослідження процесу альдольної конденсації використовували формалін, який одержували 3 параформу безпосередньо перед здійсненням процесу. Дослідження проводили в реакторі проточного типу з імпульсним подаванням реагентів і стаціонарним шаром каталізатора. Продукти реакцій аналізували методом газової хроматографії.

Результати дослідження та їх обговорення. Внаслідок виконання експериментів встановлено, що після збільшення температури конверсія ОК помітно зростає для всіх видів каталізаторів (рис. 1). Як видно з рисунка, мінімальне значення конверсії ОК становить $6 \%$ за температури $563 \mathrm{~K}$ для каталізатора 3 використанням носія $\mathrm{SnO}_{2}-\mathrm{TiO}_{2}$, а максимальне значення за цієї ж тем- ператури - 40 \% для каталізатора 3 використанням носія $\mathrm{ZrO}_{2}$. Максимальне значення конверсії ОК спостерігаємо за температури $673 \mathrm{~K}$ при часі контакту $8 \mathrm{c}-$ 88 \% для каталізатора з використанням носія $\mathrm{ZrO}_{2}$.

В усьому дослідженому інтервалі температур після збільшення температури до 623 К селективність утворення акрилової кислоти дещо підвищується (рис. 2). А вже після зростання температури від $623 \mathrm{~K}$ до $673 \mathrm{~K}$ плавно зменшується для всіх досліджених каталізаторів. Мінімальне значення селективності АК спостерігаємо за температури $673 \mathrm{~K}$ для каталізатора $\mathrm{ZrO}_{2}$, як становить всього 3 \%. Найвищі значення селективностей спостерігаємо за температури $648 \mathrm{~K}$ для каталітичних систем $\mathrm{SnO}_{2}-\mathrm{TiO}_{2}$ та $\mathrm{TiO}_{2}$ анатаз $3 \mathrm{TiO}(\mathrm{OH})$, а саме $94 \%$.

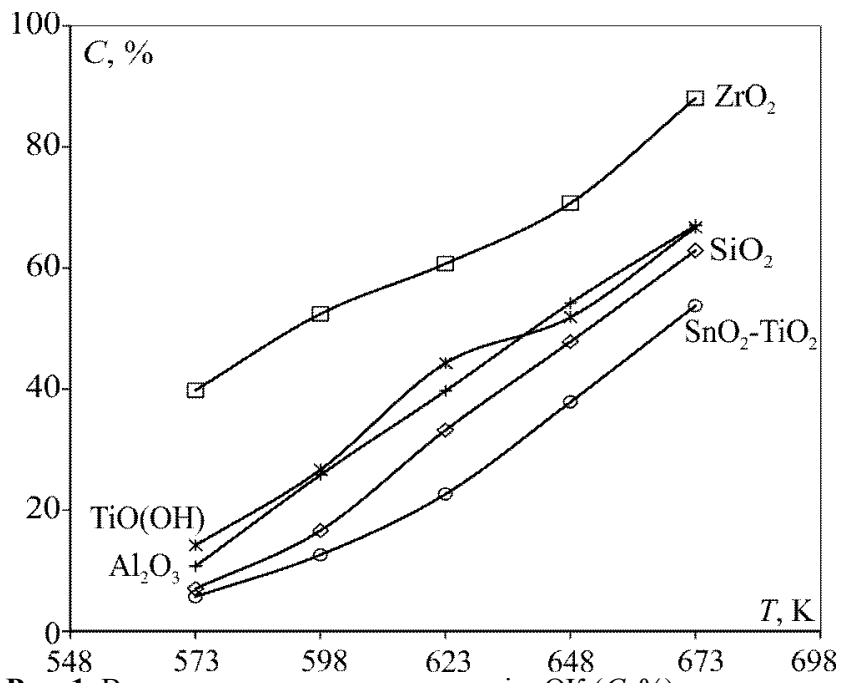

Рис. 1. Вплив температури на конверсію ОК $(C, \%)$ у присутності різних носіїв. Мольне співвідношення ОК: $Ф A=1: 1$, час контакту $8 \mathrm{c}$

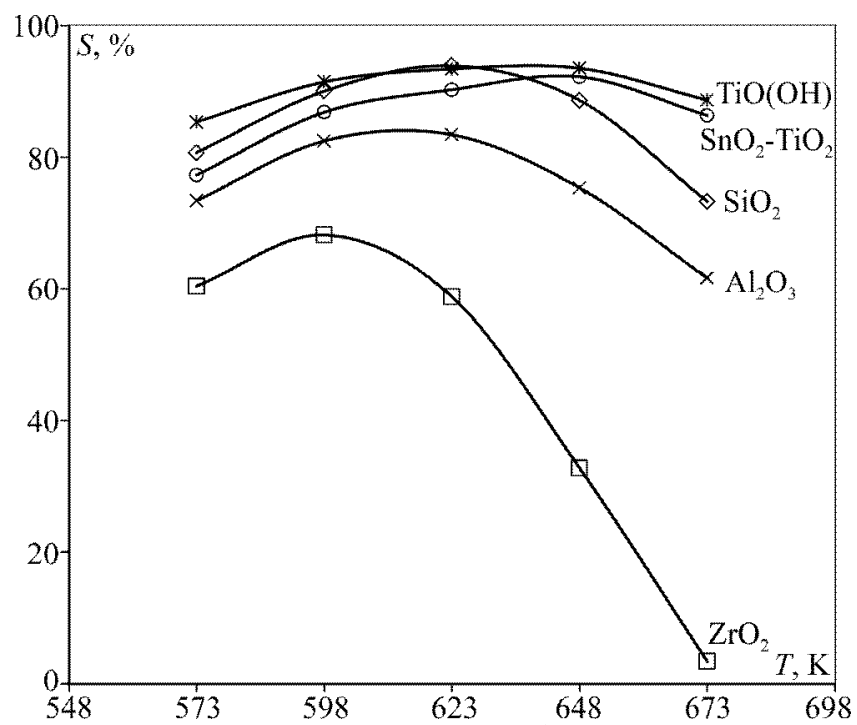

Рис. 2. Вплив температури на селективність утворення

АК $(S, \%)$ у присутності різних носіїв. Мольне співвідношення OK: $Ф A=1: 1$, час контакту $8 \mathrm{c}$

На рис. 3 наведено значення виходу АК (Y, \%) у присутності різних носіїв в інтервалі температур від 573 К до 673 К. Вихід АК для всіх каталітичних систем зростає до температури 648 К, а після підвищення температури до $673 \mathrm{~K}$ вихід АК неістотно зменшується для каталізатора на $\mathrm{Al}_{2} \mathrm{O}_{3}$, а для каталізатора на $\mathrm{ZrO}_{2}$ різко зменшується. Як видно з рис. 3 , максимальне значення виходу АК спостерігаємо за температури процесу 673 К 
i становить $59 \%$ для каталізатора на $\mathrm{TiO}_{2}$ анатаз 3 $\mathrm{TiO}(\mathrm{OH})$. Оптимальним часом контакту є 8 с за температури 648 К; вихід АК при цьому становить $49 \%$.

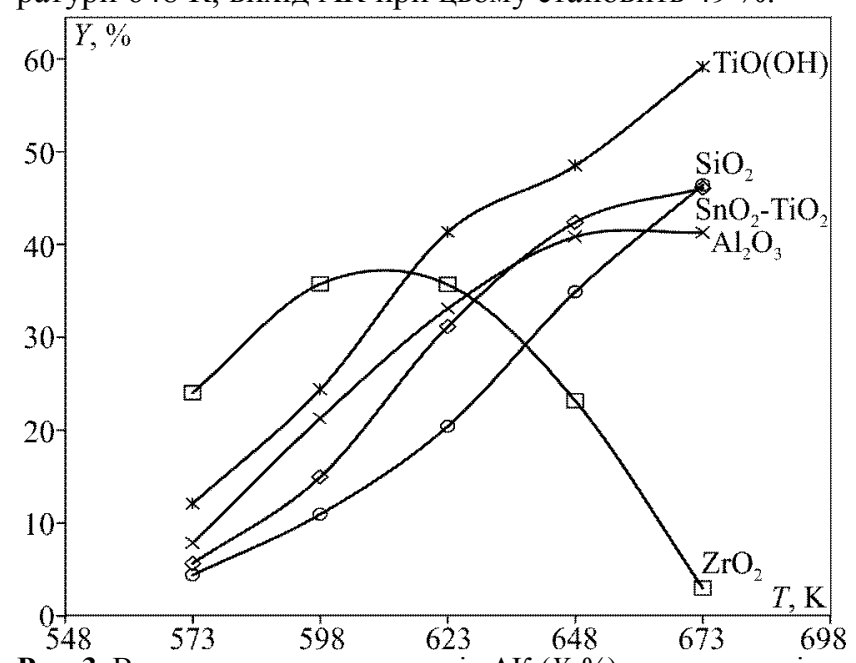

Рис. 3. Вплив температури на вихід АК $(Y, \%)$ у присутності різних носіїв. Мольне співвідношення ОК: ФА=1:1, час контакту $8 \mathrm{c}$

Отже, оптимальними умовами здійснення процесу конденсації ОК з ФА в АК є температура 648 К та час контакту $8 \mathrm{c}$ на каталізаторі 3 використанням носія $\mathrm{TiO}_{2}$ анатаз з $\mathrm{TiO}(\mathrm{OH})$. У зазначених умовах вдалося досягти виходу акрилової кислоти $49 \%$ за селективності iii утворення 94 \% та конверсії ОК 52 \%. У таблиці наведено ефективність досліджених каталізаторів в оптимальних умовах.

Таблиця. Каталітичні властивості B-P-W-V-O каталізаторів на різних носіях

\begin{tabular}{|c|c|c|c|c|c|}
\hline Параметр Носій & $\mathrm{SiO}_{2}$ & $\mathrm{Al}_{2} \mathrm{O}_{3}$ & $\mathrm{TiO}_{2}$ & $\begin{array}{c}\mathrm{SnO}_{2^{-}} \\
\mathrm{TiO}_{2}\end{array}$ & $\mathrm{ZrO}_{2}$ \\
\hline $\begin{array}{c}\text { Конверсія } \\
\text { ОК, \% }\end{array}$ & 48 & 54 & 52 & 38 & 71 \\
\hline $\begin{array}{c}\text { Селективність } \\
\text { АК, \% }\end{array}$ & 89 & 76 & 94 & 92 & 33 \\
\hline Вихід АК, \% & 43 & 41 & 49 & 35 & 23 \\
\hline $\begin{array}{c}\text { Розмір пор } \\
\text { (носія), нм }\end{array}$ & 7,9 & 12,1 & 11,6 & 10,8 & 8,8 \\
\hline
\end{tabular}

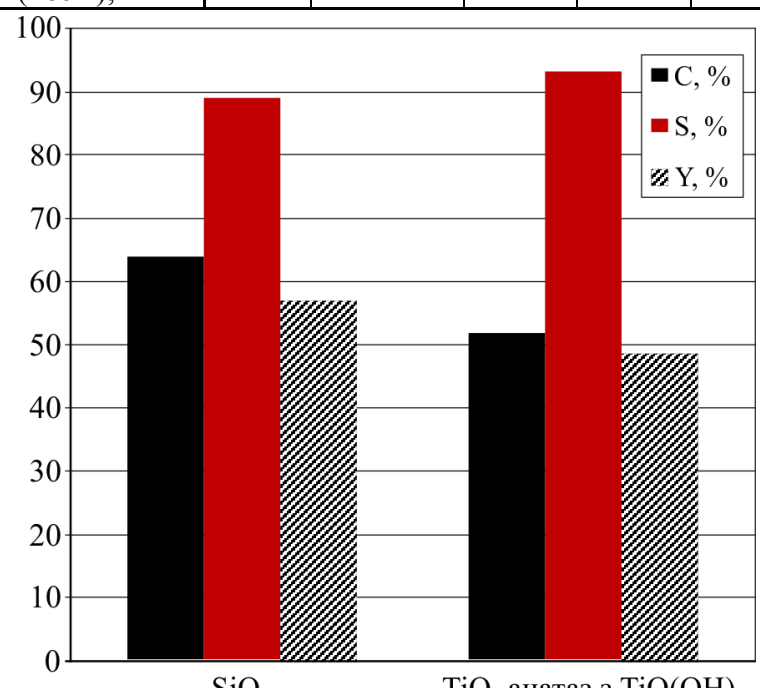

Рис. 4. Порівняння каталітичної активності оптимального каталізатора носій силікагель та носій $\mathrm{TiO}_{2}$ анатаз з $\mathrm{TiO}(\mathrm{OH})$

Під час використання каталізатора $\mathrm{B}_{2} \mathrm{O}_{3}-\mathrm{P}_{2} \mathrm{O}_{5}-\mathrm{WO}_{3}-$ $\mathrm{V}_{2} \mathrm{O}_{5} / \mathrm{SiO}_{2}$, носій силікагель марки КСКГ (питома поверхня $\left.500 \mathrm{~m}^{2} / \Gamma\right)$, приготованого методом просочування iз випаровуванням на водяній бані, в аналогічних умо- вах здійснення реакції вихід акрилової кислоти становить $57 \%$ за селективності ії утворення 89 \% та конверсії ОК 64 \% (рис. 4).

Висновки. Досліджено закономірності здійснення процесу альдольної конденсації оцтової кислоти з формальдегідом в акрилову кислоту в газовій фазі під час використання носіїв різної природи: $\mathrm{SiO}_{2}, \mathrm{TiO}_{2}$ анатаз 3 $\mathrm{TiO}(\mathrm{OH}), \mathrm{ZrO}_{2}, \mathrm{SnO}_{2}-\mathrm{TiO}_{2}, \mathrm{Al}_{2} \mathrm{O}_{3}$. B-P-W-V-O каталізатори нанесені $\mathrm{SiO}_{2}, \mathrm{TiO}_{2}$ анатаз $3 \mathrm{TiO}(\mathrm{OH}), \mathrm{ZrO}_{2}$, $\mathrm{SnO}_{2}-\mathrm{TiO}_{2}$ та $\mathrm{Al}_{2} \mathrm{O}_{3}$ з розміром пор близько 10 нм показують високу ефективність. Водночас, вихід цільового продукту, як і селективність його утворення під час використання різних носіїв, відрізняється, що свідчить про вплив природи носія на каталітичні властивості. Оптимальною температурою для здійснення процесу $є$ температура $648 \mathrm{~K}$ і час контакту 8 с. У зазначених умовах вдалося досягти виходу акрилової кислоти 49 \% за селективності їі утворення $94 \%$ та конверсії ОК $52 \%$ на каталізаторі 3 використанням носія $\mathrm{TiO}_{2}$ анатаз 3 $\mathrm{TiO}(\mathrm{OH})$.

\section{Перелік використаних джерел}

Bailey, O. H., Montag, R. A., \& Yoo, J. S. (1992). Methacrylic acid synthesis. Applied Catalysis A: General, 88(2), 163-177. https://doi.org/10.1016/0926-860X(92)80213-V

Cuncun, Zuo, Yaping, Li, Chunshan, Li, Shasha, Cao, Haoyu, Yao, \& Suojiang Zhang. (2015). Thermodynamics and separation process for quaternary acrylic systems. AlChE $J$, 62, 228-240. https://doi.org/10.1002/aic.15015.

Danner, H., Ürmös, M., Gartner, M., \& Braun, R. (2008). Biotechnological Production of Acrylic Acid from Biomass. Applied Biochemistry and Biotechnology, 70, 887-894. https://doi.org/10.1007/BF02920199.

Killian Flégeau, Richard Pace, Hélène Gautier, Gildas Rethore, Jerome Guicheux, Catherine Le Visage, \& Pierre Weiss. (2017). Toward the development of biomimetic injectable and macroporous biohydrogels for regenerative medicine. Advances in Colloid and Interface Science. https://doi.org/10.1016/j.cis.2017.07.012.

Li, X., \& Zhang, Y. (2016). Highly Efficient Process for the Conversion of Glycerol to Acrylic Acid via Gas Phase Catalytic Oxidation of an Allyl Alcohol Intermediate. ACS Catalysis, 6, 143150. https://doi.org/10.1021/acscatal.5b01843.

Mamoru Ai, Hideyuki Fujihashi, Sanae Hosoi, \& Akiyo Yoshida. (2003). Production of methacrylic acid by vapor-phase aldol condensation of propionic acid with formaldehyde over silicasupported metal phosphate catalysts. Applied Catalysis A: General, 252(1), 185-191. https://doi.org/10.1016/S0926-860X(03)00449-6

Nebesnyi, R. V., Pikh, Z. H., Ivasiv, V. V., Sydorchuk, V. V., Shpyrka, I. I., \& Lapychak, N. I. (2016). Pidvyshchennia efektyvnosti b2o3-p2o5-wo3-v2o5/sio2 katalizatora protsesu aldolnoi kondensatsii otstovoi kysloty $\mathrm{z}$ formaldehidom hidrotermalnoiu obrobkoiu nosiia. Visnyk Natsionalnoho universytetu "Lvivska politekhnika". Khimiia, tekhnolohiia rechovyn ta yikh zastosuvannia, 841, 113-118. [In Ukrainian].

Nebesnyi, R., Ivasiv, V., Dmytruk, Y., \& Lapychak, N. (2013). Acrylic acid obtaining by acetic acid catalytic condensation with formaldehyde. Eastern-European Journal of Enterprise Technologies, 6/6(66), 40-42. [In Ukrainian].

Patent 0343319 US. (2014). Process for preparing acrylic acid with high space-time ield. Goebel M. BASF SE., filing date: 18.05.2013; publication date: 08.04.2014.

Patent 7553918 US. (2009). pH-sensitive polymer. Petereit, Hansulrich (Darmstadt, DE), Meier, Christian (Darmstadt, DE), Schultes, Klaus (Wiesbaden, DE) and others; assignee: Roehm GmbH \& Co. KG (Darmstadt, DE), Universite de Montreal (Montreal, CA). - № 510371; filing date: 22.10.2002; publication date: 30.06 .2009 . 
Patent 7563265 US. (2009). Apparatus for strengthening vertebral bodies. Murphy, Kieran P. J. (119 Beechdale Rd., Baltimore, MD, US); Assignee: Brinks Hofer Gilson \& Lione. - № 594685; filing date: 16.06.2000; publication date: 21.07.2009.

Patent 7655706 US. (2010). Polymethylmethacrylate bone cement. Kühn, Klaus-dieter (Marburg, DE), Vogt, Sebastian (Erfurt, DE); assignee: Heraeus Kulzer GmhH (Hanau, DE). - № 447807; filing date: 06.06.2006; publication date: 02.02.2010.

Shashkova, V. T., Matveeva, I. A., Glagolev, N. N., Zarkhina, T. S., Cherkasova, A. V., Kotova, S. L., Timashev, P. S., \& Solovieva, A. B. (2016). Synthesis of polylactide acrylate derivatives for the preparation of 3D structures by photo-curing. Mendeleev
Communications,

26

$418-420$.

https://doi.org/10.1016/i.mencom.2016.09.018.

Skubiszewska-Zieba, J., Khalameida, S., \& Sydorchuk, V. (2016). Comparison of surface properties of silica xeroand hydrogels hydrothermally modified using mechanochemical, microwave and classical methods. Colloids and Surfaces A: Physicochemical and Engineering Aspects, 504, 139-153. https://doi.org/10.1016/j.colsurfa.2016.05.066

Zhyznevskyy, V. M., Nebesnyy, R. V., Ivasiv, V. V., \& Shybanov, S. V. (2010). Obtaining of acrylic monomers by gas-phased catalytic condensation of carbonyl compounds in gas phase. Reports of NAS Ukraine, 10, 114-118. [In Ukrainian].

\section{И. И. Шпирка', Р. В. Небесний1, З. Г. Пих1, В. В. Сидорчук², С. В. Халамейда², О. В. Цимбалиста', Х. Р. Хома' \\ ${ }^{1}$ Начиональный университет "Львовская политехника", г. Львов, Украина \\ ${ }^{2}$ Институт сорбции и проблем эндоэкологии НАН Украины, г. Киев, Украина}

\section{ПОЛУЧЕНИЕ АКРИЛОВОЙ КИСЛОТЫ АЛЬДОЛЬНОЙ КОНДЕНСАЦИЕЙ УКСУСНОЙ КИСЛОТЫ С ФОРМАЛЬДЕГИДОМ В ПРИСУТСТВИИ В-P-W-V-Ox КАТАЛИЗАТОРОВ НА МЕЗОПОРИСТЫХ НОСИТЕЛЯХ}

Исследовано влияние различных типов мезопористых носителей для $\mathrm{B}-\mathrm{P}-\mathrm{W}-\mathrm{V}-\mathrm{O}_{\mathrm{x}}$ катализатора, а именно $\mathrm{SiO}_{2}, \mathrm{TiO}_{2}$, $\mathrm{ZrO}_{2}, \mathrm{SnO}_{2}-\mathrm{TiO}_{2}$ и $\mathrm{Al}_{2} \mathrm{O}_{3}$ на их эффективность в процессе альдольной конденсации уксусной кислоты с формальдегидом с образованием акриловой кислоты. Катализаторы готовили методом пропитки носителя насыщенным раствором компонентов активной фазы. Каталитические свойства полученных катализаторов исследованы в реакции альдольной конденсации уксусной кислоты с формальдегидом в температурном диапазоне от 573 до $673 \mathrm{~K}$, времени контакта 8 с при эквимолярном соотношении исходных реагентов. Установлено влияние условий осуществления процесса (температуры и времени контакта) на параметры процесса конденсации уксусной кислоты с формальдегидом; установлены оптимальные условия осуществления процесса. Оптимальными условиями осуществления процесса конденсации уксусной кислоты с формальдегидом в акриловую кислоту является температура $648 \mathrm{~K}$ и время контакта 8 с на катализаторе с использованием носителя $\mathrm{TiO}_{2}$ анатаз с $\mathrm{TiO}(\mathrm{OH})$. В указанных условиях удалось достичь выхода акриловой кислоты $49 \%$ при селективности ее образования $94 \%$ и конверсии уксусной кислоты $52 \%$. Показано, что катализаторы на основе носителей различной природы с размером пор около 10 нм позволяют получать акриловую кислоту с высоким выходом и селективностью. В то же время, выход целевого продукта, как и селективность его образования при использовании различных носителей отличается, что свидетельствует о влиянии природы носителя на каталитические свойства.

Ключевые слова: акрилатные мономеры; гетерогенный катализ; твердые катализаторы; метод пропитки.

\section{I. Shpyrka1, R. V. Nebesnyi', Z. G. Pikh1, V. V. Sydorchuk' ${ }^{2}$, S. V. Khalameida', O. V. Tsymbalista', K. R. Khoma ${ }^{1}$ \\ ${ }^{1}$ Lviv Polytechnic National University, Lviv, Ukraine \\ ${ }^{2}$ Institute for Sorption and Problems of Endoecology of NAS of Ukraine, Kyiv, Ukraine}

\section{ACRYLIC ACID OBTAINING BY ALDOL CONDENSATION OF ACETIC ACID WITH FORMALDEHYDE IN THE PRESENCE OF B - P-W - V-0 CATALYSTS ON MESOPOROUS CARRIER}

The purpose of the work was to determine the influence of different mesoporous carriers: $\mathrm{SiO}_{2}, \mathrm{TiO}_{2}$ anatase of $\mathrm{TiO}(\mathrm{OH}), \mathrm{ZrO}$, $\mathrm{SnO}_{2}-\mathrm{TiO}_{2}, \mathrm{Al}_{2} \mathrm{O}_{3}$ on their efficiency in the process of aldol condensation of acetic acid with formaldehyde with the formation of acrilyc acid. To achieve this goal, the following tasks must be solved. Firstly, it is necessary to investigate the ability of the developed catalyst to intensify the process of acrylic acid production and to determine the optimal parameters of the process. Secondly, we should establish dependence of selectivity, yield of acrylic acid and conversion of reagents from temperature. The catalysts were prepared by impregnating the carrier with a saturated solution of the active phase components. The atomic ratio of components in catalyst $\mathrm{B}: \mathrm{P}:(\mathrm{W}+\mathrm{V})$ is $3: 1: 0.3$; atomic ratio is $\mathrm{W}: \mathrm{V}=2: 3$. The catalytic properties of the obtained catalysts were investigated in the reaction of aldol condensation of acetic acid with formaldehyde at the temperature range from 573 to $673 \mathrm{~K}$, the contact time of $8 \mathrm{~s}$ with the equimolar ratio of the initial reagents. $\mathrm{B}-\mathrm{P}-\mathrm{W}-\mathrm{V}-\mathrm{Ox}$ catalysts that were applied on $\mathrm{SiO}_{2}, \mathrm{TiO}_{2}$ anatase of $\mathrm{TiO}(\mathrm{OH}), \mathrm{ZrO}_{2}, \mathrm{SnO}_{2}-\mathrm{TiO}_{2}$ and $\mathrm{Al}_{2} \mathrm{O}_{3}$ carriers with a size of pore about $10 \mathrm{~nm}$ showed high efficiency. At the same time, the yield of the product as well as the selectivity of its formation were different when various different carriers were used, indicating the influence of carrier nature on the catalytic properties of the carrier. The effect of the process conditions (temperature and contact time) on the parameters of condensation of acetic acid with formaldehyde has been determined. The optimum temperature for carrying out the process is $648 \mathrm{~K}$ and a contact time -8 seconds. Under these conditions it was possible to achieve $49 \%$ acrylic acid yield with a selectivity of $94 \%$ and conversion of acetic acid $52 \%$ using catalyst $\mathrm{TiO}_{2}$ anatase with $\mathrm{TiO}(\mathrm{OH})$. It has been demonstrated that the catalysts based on carriers with different nature and pore size near $10 \mathrm{~nm}$ allows acrylic acid synthesis with high yield and selectivity. The comparison of the catalytic activity of the optimal catalyst with silica gel and the $\mathrm{TiO}_{2}$ anatase carrier with $\mathrm{TiO}(\mathrm{OH})$ were shown.

Keywords: pore size; heterogeneous catalysis; solid catalysts; method of impregnation. 